Research Article

\title{
Spectrum of nontraumatic perforation peritonitis: a prospective study of 277 cases with special reference to morbidity and mortality
}

\author{
Rishi Kumar Garg*, Rachna Gupta, Yogesh Kailasia, Akash Singh Chhari, \\ Mayank Jain, Chandrashrekhar Dubey
}

Department of Surgery, S.S. Medical College, Rewa, Madhya Pradesh, India

Received: 23 April 2016

Accepted: 05 May 2016

*Correspondence:

Dr. Rishi Kumar Garg,

E-mail: gargrishi626@gmail.com

Copyright: () the author(s), publisher and licensee Medip Academy. This is an open-access article distributed under the terms of the Creative Commons Attribution Non-Commercial License, which permits unrestricted non-commercial use, distribution, and reproduction in any medium, provided the original work is properly cited.

\begin{abstract}
Background: Gastrointestinal perforation constitutes one of the most common causes of surgical emergency. The main objective was to study different causes of perforation peritonitis and there sign, symptom. Factors affecting morbidity and mortality.

Methods: It was prospective 1 year study conducted in surgical ward of Department of surgery SGMH Rewa (M.P.) during the period August 2014-July 2015.A total of 277 cases of gastrointestinal perforation peritonitis were studied. Patients are selected on the basis of symptom, sign at the time of admission and operative finding. All patients have been studied and results are compared with previous similar studies.

Results: Abdominal pain was present in all cases of perforation peritonitis. $89.9 \%$ of patient had distension of abdomen, $79.9 \%$ complained of fever and $34.3 \%$ with vomiting. On per abdominal examination tenderness and distension was present in all cases of perforation. $96.5 \%$ of cases had guarding/rigidity. $82.7 \%$ of cases had gas under the diaphragm with majority of them in peptic ulcer perforation and minimum in appendicular perforation.

Conclusions: Patient with higher age group had higher mortality compare to younger age group. Mortality was maximum $32 \%$ in age group of $>60$ years. Overall mortality in our study was $12.63 \%$ and was due to delayed presentation to hospital, delayed operative intervention due to shock and septicaemia, with co-morbidity being the additive factors.
\end{abstract}

Keywords: Perforation, Distribution, Mortality

\section{INTRODUCTION}

Abdomen is a "Magic Box" presenting various clinical conditions of varied aetiology, which require early recognition and proper management and timely intervention to prevent life threatening complications. Peritonitis is an inflammatory condition of the peritoneum. The process may be acute or chronic; it may be septic or aseptic and primary or secondary.

Perforation of peptic ulcer is common cause of morbidity and mortality in patients of peptic ulcer disease. ${ }^{1}$
Although the incidence of peptic ulcer disease has declined during last three decades, due to $\mathrm{H}_{2}$ receptor antagonists and proton-pump inhibitors, although the incidence of patients who have developed perforation of peptic ulcer has increased. The demographic pattern also has changed. Previously these patients were typically young and middle aged men with a history of peptic ulcer disease, they now tend to be elderly and chronically ill patients who are often taking medications specially NSAIDS. 
Typhoid perforation though is a worldwide problem it is common in underdeveloped and developing countries, due to poor sanitation and hygiene. Despite best possible management typhoid perforation has high mortality and morbidity, mainly due to toxaemia.

Appendicular perforation is less common than that of peptic and typhoid. Though no age is exception, it is common in pre-school age group.

The management of gastrointestinal perforation is surgical primarily. In the past there were discussions on overall outcome of surgical interventions and conservative treatment was especially advocated in patients unfit for surgery. But now with advent of better preoperative management, investigation and surgical technique management of these patients has improved. Despite all this Perforation peritonitis still remains a potentially fatal condition.

With the changing pattern of gastrointestinal perforation, the present study has been undertaken to study the various aspects related to incidence, aetiology, and presentation of perforation peritonitis, its management and outcome patterns.

\section{METHODS}

A total of 277 patients of gastrointestinal Perforation, admitted in the surgical wards of Department of Surgery, ShyamShah Medical College and associated Sanjay Gandhi Memorial Hospital, Rewa (M. P.) during period of 1stAugust 2014 to 31th July 2015.

\section{Inclusion criteria}

All cases of perforation peritonitis admitted in surgical wards during the study period.

\section{Exclusion criteria}

Cases of perforation which could not be operated.

All patients suspected of perforation peritonitis with symptoms of sudden onset of pain in abdomen, distension of abdomen, absolute constipation, vomiting were admitted to surgery ward from outpatient department, casualty in emergency or transferred from wards of other Departments. Clinical diagnosis of perforation peritonitis is made based on history and physical examination which will be confirmed by investigations or by laparotomy formed the basis of selection of cases.

On admission rapid general survey and quick resuscitation was started after that every patient was registered with details such as name, age, sex, residence, occupation, socioeconomic status. Complaints of pain in abdomen, distension of abdomen, fever, constipation, vomiting etc recorded with duration. History of similar complaints in the past, analgesics or steroids use, tobacco chewing, smoking, alcohol was recorded. History of hypertension, diabetes mellitus, chronic obstructive pulmonary disease, tuberculosis, history of previous operation and treatment was recorded. A thorough general examination and detailed systemic examination was done.

The per abdomen examination included careful examination of the abdomen with special reference to the distension, tenderness, guarding, rigidity, obliteration of liver dullness, shifting dullness, bowel sounds and digital rectal examination.

Routine blood investigation including complete hemogram, blood grouping, HIV, HBsAG, blood urea, serum creatinin, setrum electrolyte, urine examination including albumin, sugar. Erect abdomen $\mathrm{x}$ ray to detect free gas under diaphragm (lateral decubitus $\mathrm{X}$ rays in unstable patient) widal test was done in suspected enteric perforation, 4 quadrant abdominal paracentesis was done only in selected cases ( just for conformation in cases where $\mathrm{x}$ ray showed no gas under the diaphragm), ultrasonography were also performed in some cases.

Intra-peritoneal drainage was done in patients who had too low general condition to undergo general anaesthesia. Intra-peritoneal drainage was done under local anaesthesia. Tube drain was put intra-peritoneally through a midline infra-umbilical incision.

Antibiotics like Ceftriaxone or piperacillin with sulbactum, amikacin and metronidazole 500mg TID were used in all cases. Antibiotic were changed according to culture and sensitivity report. Laparotomy was done under general anaesthesia. Midline incision was taken depending upon the suspected site of pathology either upper or lower was made depending on the suspected site of perforation. Viscera were inspected carefully, site of perforation located and appropriate surgical procedure was performed. Peritoneal toilet with normal saline was done and peritoneal cavity was drained, postoperatively patients were put on continuous nasogastric aspiration, intravenous fluid and antibiotics. Vital signs were monitored, assessment of intake and output and biochemical parameters etc. were done. Recovery of the patients was observed and any complications which occurred during the course were noted. Regular follow up of the patients were carried out.

\section{RESULTS}

In the study incidence of cases of non-traumatic perforation peritonitis was $3.34 \%$ of total admissions and $20.51 \%$ of total acute abdomen cases. Maximum numbers of perforations (28\%) were recorded in month of August.

The most common aetiological factor in the presentation of disease peptic disease $(58.48 \%)$ followed by typhoid $(30.32 \%)$, appendicular perforation $(4.33 \%)$. 
Table 1: Aetiology of perforation.

\begin{tabular}{|lll|}
\hline Aetiological & No. of cases & Percentages \\
\hline Peptic & 162 & $58.48 \%$ \\
\hline Typhoid & 84 & $30.32 \%$ \\
\hline Appendicular & 12 & $4.33 \%$ \\
\hline Non-specific inflammation & 12 & $4.33 \%$ \\
\hline Tuberculosis & 07 & \\
\hline
\end{tabular}

\section{Site of perforation}

Commonest site for perforation was Stomach in $117(72.22 \%)$ patients out of which pyloric part was involved in $95 \%$, followed by ileum in 91 (32.85\%), duodenum in $(27.77 \%)$, appendix (12), jejunum (7), large bowel (5) were other site.

\section{Age incidence}

Most of the patients belonged to 21-40 age group. The mean age was 30 years. Peptic perforation were common in age group 41-60 years $(22.74 \%)$, followed by $21-40$ years of age $(22.38 \%)$. Typhoid perforation were common in age group of $21-40$ years $(13.71 \%)$, followed by 0 - 20 years of age (11.19\%). Appendicular Perforation were common in age group of 21-40 years (2.52\%), followed by $41-60$ years of age $(1.08 \%)$. In case of Tubercular perforation highest incidence were reported in age $<40$ years $(2.16 \%)$.

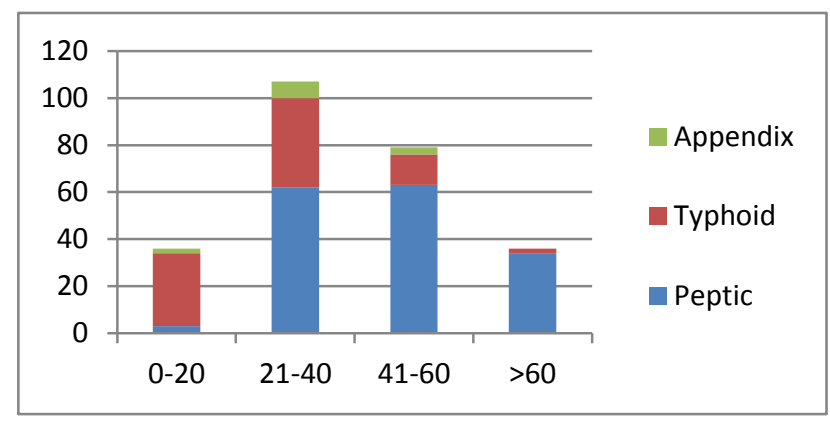

Figure 1: Age incidence.

\section{Sex incidence}

Male were predominantly affected. Overall male:female ratio 5.6:1 (Figure 2).

\section{Residence}

Perforation peritonitis more common in rural population (Figure 3).

\section{Symptoms}

Pain abdomen was present in all cases of perforation. Only 95 of 277 cases had vomiting (34.3\%). Distension was seen in $249(89.9 \%)$, constipation in $228(82.3 \%)$ and fever in $202(72.9 \%)$ which was moderate degree and not associated with chills and rigors (Table 2).

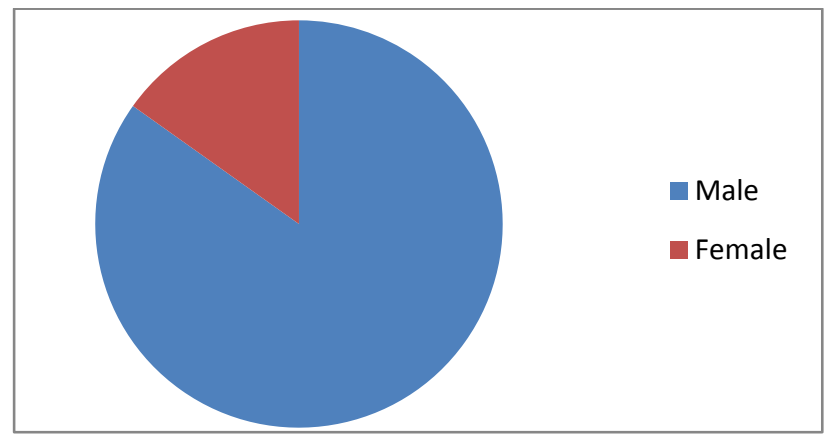

Figure 2: Sex ratio.

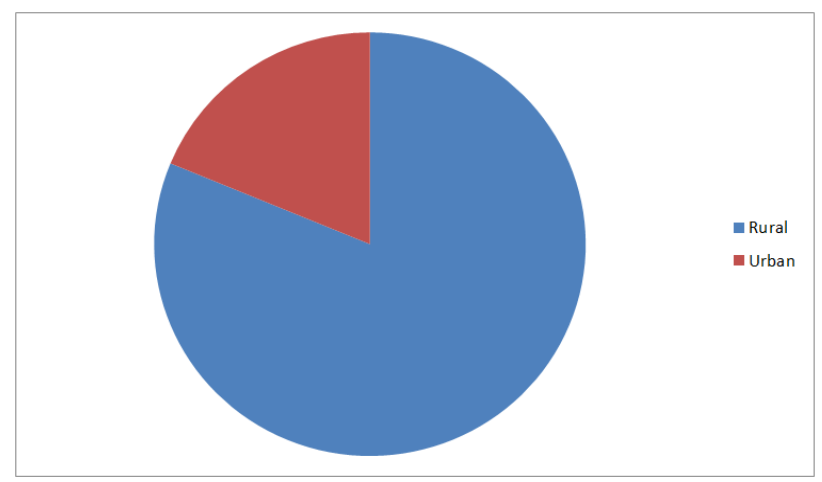

Figure 3: Residence.

Table 2: Different types of symptoms.

\begin{tabular}{|lll|}
\hline Symptoms & Numbers of cases & Percentages \\
\hline Pain abdomen & 277 & 100 \\
\hline Abdominal distension & 249 & 89.9 \\
\hline Constipation & 228 & 82.3 \\
\hline Fever & 202 & 72.9 \\
\hline Vomiting & 95 & 34.3 \\
\hline
\end{tabular}

\section{Signs}

Tenderness and distension was present in all cases of perforation. In peptic perforation there was guarding in $98.8 \%$ cases and absent Bowel sounds in $96.3 \%$. In case of Typhoid perforation; there was guarding $96.4 \%$ and absent bowel sounds in $95.2 \%$. In appendicular perforation there was guarding $91.7 \%$ and absent bowel sounds in $75 \%$.In Tubercular perforation there was guarding and absent bowel sounds present in $86 \%$ cases.

Table 3: Different signs on presentation.

\begin{tabular}{|ll|l|}
\hline Abdominal signs & Number of patients & Percentage \\
\hline Tenderness & 277 & 100 \\
\hline Distension & 277 & 100 \\
\hline Guarding/rigidity & 268 & 96.8 \\
\hline $\begin{array}{l}\text { Absent bowel } \\
\text { sound }\end{array}$ & 260 & 93.9 \\
\hline
\end{tabular}


Scout film of abdomen in standing position showing both dome of diaphragm was taken in all cases. Commonest findings was gas under diaphragm $(82.7 \%)$ followed by haziness $(41.2 \%)$.

Intra-operatively, the amount of peritoneal free fluid seen and its nature was noted and contamination was classified as mild, moderate or severe. Mild contamination with seropurulent fluid, seen in $108(39 \%)$ patients, moderate contamination in $65(23.5 \%)$ while severe contamination, consisting of bile stained or feculent fluid with fibrin and pus flakes was seen in $40(14.4 \%)$ patients.

\section{Treatment}

All the patient with peptic perforation were treated with omentopexy with or without primary closer and in case of ileal perforation primary closer with or without ileostomydepent on general condition of patient and contamination of peritoneal cavity. Appendicular perforation treated with simple appendectomy. Colon perforation treated as primary closer with or without ileostomy and jejunal perforation treated by primary closer.

\section{Mortality}

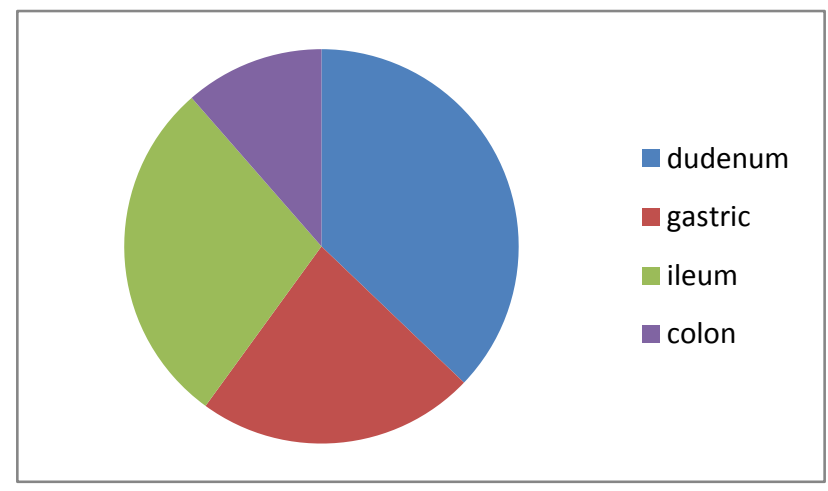

Figure 4: Mortality in perforation.

Overall mortality was $12.63 \%$ which was higher in age group $>60$ yrs. Maximum mortality in case of peptic perforation $(7.58 \%)$. Operative interval was taken as the time from the onset of first symptom till the patient was treated surgically. In case of peptic perforations which were operated before 72 hours mortality was $5.35 \%$, which was less than those operated after 72 hours $(16.98 \%)$. Mortality in case of Intra-peritoneal drainage followed by operation was $12.06 \%$, which was less than patient that operated without intra-peritoneal drainage (13.11\%). Peptic Perforation operated by simple closure + omentopexy had a mortality $11.53 \%$ which was lower than that patients operated by Omentopexy only (13.63\%). It is evident from above table that Mortality in cases of Typhoid Perforation was $11.9 \%$. In cases of Typhoid Perforations that were operated before 72 hour mortality was $8.33 \%$ which was less than that operated after 72 hour (13.33). In case of intraperitoneal drainage followed by definitive repair mortality was $11.11 \%$ which was comparatively similar than that operated directly by definitive repair $(12.12 \%)$. In the cases of typhoid perforation that were operated by primary repair mortality was $17.39 \%$ that was significantly more than those which were operated by primary repair + ileostomy $(5.26 \%)$.

\section{Post-operative complications}

Most common complication recorded in this was suture site infection $(52.45 \%)$ and respiratory infection/distress $(36.88 \%)$. Mortality in our study was $12.63 \%$ and was due to septicaemia with older age group, delayed presentation to Hospital and other associated comorbidity being the additive factors.

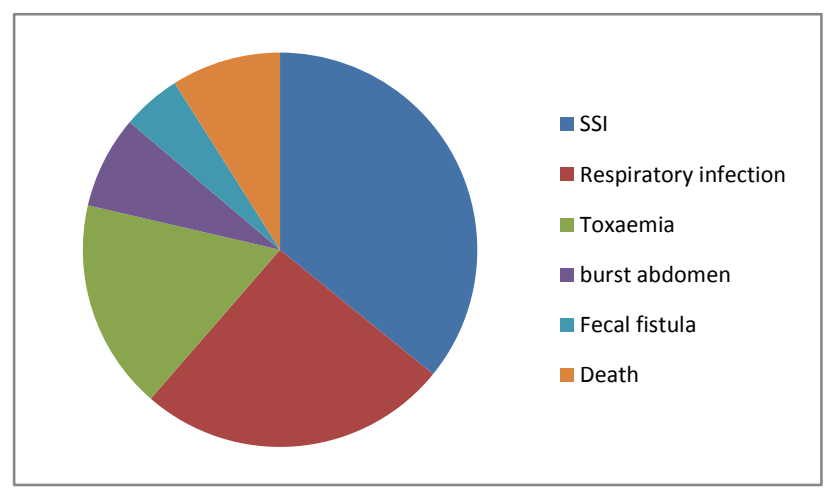

Figure 5: Complication.

\section{Hospital stay}

Average hospital stay in case of typhoid perforation was 16 days which was maximum. In case of peptic perforation hospital stay was 12 days, in appendicular perforation 9 days, in tubercular perforation average stay was 13 days and case of jejunal and colon perforation it was 15 days.

\section{DISCUSSION}

Non traumatic gastrointestinal perforation forms a formidable proportion of acute abdomen cases admitted as surgical emergency. The relative incidence of various types of perforations is variable. ${ }^{1,2}$ there is definitely is regional bias in frequency and incidence of perforations, with enteric perforations, being encountered more frequently in developing countries of south east Asia, and colonic perforations in the far east. In India, peptic perforation is the commonest followed by enteric, tubercular, appendicular. ${ }^{1,3-5}$ Enteric and upper intestinal pathology is common in developing nations as in Asia due to poor socio-economic condition and stressful lifestyles. In western countries due to lifestyle and dietary habits, along with genetic predisposition, large bowel pathology is common. 
Majority of patients was belonged to the age group of 25 to 35 years in most of the studies ${ }^{6,7}$ except Afridi et $\mathrm{al}^{8}$ who reported majority of them being in age group of 35 45 years. Mean age in our study was 30 which was comparable to that Yadav et $\mathrm{al}^{6}$, who reported the mean age to be 33.9 yrs. Males were seen to predominate in incidence in all the studies ${ }^{6-8}$. The highest male preponderance was noticed by Jhobtaet $\mathrm{al}^{7}$, where the ratio of male to female was 5.2:1, followed by Yadav et al6 where the ratio was $4.9: 1$, which was almost similar to our study in which the ratio was 5.6:1. The most common symptom in all the study groups was pain abdomen in general. In our study all the patients (100\%) had pain abdomen which was quite comparable to be the most common mode of presentation. Yadavet $\mathrm{al}^{6}$ who reported $73.6 \%$ quite predominantly comparable to our study. In our studyabdominal distension more common (89.9\%) than study done previously. This may be because of most patient present in our study late in stage of general peritonitis and taking home remedy. 202 of 277 patients $(72.9 \%)$ gave a history of fever. The other studies quoted here showed a significant difference in the presentation of fever who reported quite less number of patients with fever as compare to our study. Site of perforation was one of the important parameter of the studies. Doraijanet $\mathrm{al}^{9}$ study the perforation on the basis of site of perforation, aetiology of perforation and mortality. Similar was the case with Khan et al ${ }^{10}$ who study the same parameters. The most common site of perforation was seen to be at the gastroduodenal region due to the fact that most patients had predisposing acid peptic disease. The highest incidence of acid peptic disease is thought to be unnecessary use of NSAIDS and improper timing of food in most patients. Also the $\mathrm{H}$ pylori infection is a major cause. In discovery of PPI and other antacids have reduced the incidence of perforations due to acid peptic disease. In our study we found $58.48 \%$ patients having perforation at the gastroduodenal region, which was more than studies by Doraijanet $\mathrm{al}^{9}(32 \%)$ and Khan et $\mathrm{al}^{10}(38.8 \%)$. This because of over the counter use of analgesic, steroid and most of the patient in our study from rural, old age population. Perforations due to peptic ulcer disease were seen to be the most common cause of perforations consistently in all studies except that of Doraijan et $\mathrm{al}^{9}$, who showed that the majority of the perforations were due to tuberculosis $(66.9 \%)$. Our study showed $58.48 \%$ patient had perforations due to peptic disease which was the most common cause of perforation. This was more than studies done by Jhobtaet $\mathrm{al}^{7}$, Afridi et $\mathrm{al}^{8}$ and Yadav et $\mathrm{al}^{6}$.

Laparoscopy is feasible and safe in cases of peritonitis. Laparoscopic treatment is particularly effective in the case of appendicular and gastroduodenal perforation. In the case of colonic perforation, the conversion rate remains high with growing experience and surgical skill, more of these cases will be treated laparoscopically in the future. The laparoscopic approach for the management of appendicular peritonitis is safe and effective and does not result in any specific complication. Advantage include the high quality of laparoscopic exploration, a very low incidence of septic complications and a comfortable postoperative recovery. ${ }^{11}$ In our study due to emergency presentation, nonavailability of expert laparoscopic surgeon and equipment in an emergency setting of peripheral hospital, open surgery carried out in all cases.

Usage of drains in surgeries for perforation peritonitis is a matter of personal preference. Placing drains in the peritoneum does not improve outcome in uncomplicated perforated appendicitis. ${ }^{12}$ Routine use of drains was not effective in preventing postoperative fluid collection, in decreasing the incidence of intra-abdominal abscesses. The migration of bacteria from the exterior to the peritoneal cavity via the drain was also demonstrated. Drains were found to cause morbidity including intestinal obstruction. The routine use of drains was found to be neither safe nor effective in patients of perforated duodenal ulcer treated by omental patch closure ${ }^{13}$. By contrast, a mixed bacterial flora was responsible for most infections following appendicectomy for gangrenous or perforated appendicitis, irrespective as to use of a drain. ${ }^{14}$ We normally decide to keep a drain depending on amount of peritoneal contamination and not upon site of perforation, status of bowel being another considering factor. Hence, all patients were not left with drains in situ after the surgery.

Most common post-operative complication was suture site infection $(52.48 \%)$ and respiratory infection $(36.82 \%)$ which was second most common form of postoperative morbidity in this study. This complication was consistently common with rest of study. Toxaemia was seen in $19.22 \%$ of the patients in this study. Jhobta et $\mathrm{al}^{7}$ reported $17 \%$, Afridi et $\mathrm{al}^{8} 20 \%$ and Yadav et al6 5.2\% of their patients having a septic shock in post-operative period. Our study had mortality rate $12.63 \%$ which was quite similar to study done by Jhobtaet $\mathrm{al}^{7}$ (10\%), Afridi et $\mathrm{al}^{8}(10.6 \%)$ and Yadav et $\mathrm{al}^{6}$ had a mortality rate of $13 \%$.

Overall mortality has now decreased due to better understanding of patho-physiology, wide spread use of better preoperative resuscitation measures, better antibiotic, safer anaesthesia, early patient reporting and better post-operative management in intensive care set up as required1. Highest mortality is seen in duodenal perforation especially associated with severe peritoneal contamination.

\section{CONCLUSION}

Mortality was more in patients with delayed presentation and older age group, this can be prevented by health awareness, better primary health facility, better recruitment of heath staff who skilled in emergency management and timely referral, better transport facility, increased per person income. Surgical treatment is the most definitive treatment for perforative peritonitis 
patients and post-operative care remain extremely important in the better outcome of the patients.

A better understanding of aetiological factors, prompt medical facilities and good post-operative care needs to be carried out to further improve the outcome in gastrointestinal perforation.

Funding: No funding sources

Conflict of interest: None declared

Ethical approval: The study was approved by the institutional ethics committee

\section{REFERENCES}

1. Singh G, Sharma RK, Gupta A. Gastrointestinal perforations- a prospective study of 342 cases. Gastroenterology today. 2006;10(4):167-70.

2. Banerjee JC, Bhattacharya PB. A Handbook of tropical diseases with treatment and prescription, $6^{\text {th }}$ ed. Section 3, Chapter 1. Calcutta: Academic Publishers; 1990:220-229.

3. Dandapatt MC, Mukherjee LM, Mishra SB. Are view of 340 cases. Ind J Surg. 1991;53(5):189-93.

4. Desai LA, Mehta SJ, Nadkarni KM. A Study of factors contributing to mortality. Ind $\mathrm{J}$ Surg. 1983;45:705-10.

5. Sanjay G, Robin K. Peritonitis- the Eastern Experience World. J Emerg Surg. 2006;1:1-13.

6. Yadav D, Garg P. Spectrum of perforation peritonitis in Delhi: 77 cases Experience. Indian J Surg. 2013;75(2):133-7.

7. Jhobta RS, Attri AK, Kaushik R, Sharma R. Spectrum of perforation peritonitis in India-review 504 consecutive cases World. J Emer Surg. 2006;1:1186-749.

8. Afridi SP, MalikF, Rahman SU, Shameen H, Samo KA. Spectrum of perforation peritonitis in Pakistan;
300 cases eastern experience. World J Emer Surg. 2008;3:31.

9. Dorairajan LN, Gupta S, SuryanarayanaDeo SV, Chumber S, Sharma LK. Peritonitis in India- A decades experience. Trop Gastroenterology. 1995;16:33-8.

10. Khan S, Khan IU, Aslam S, Haque A. Retrospective analysis of abdominal surgeries at Napalgunj Medical College, Nepalgunj, Nepal: 2 years' experience. Kathmandu Uni Med J. 2004;2:336-43.

11. Navez B, Tassetti V, Scohy JJ, Mutter D, Guiot P, Evrard S et al. Laparoscopic management of acute peritonitis. Br J Surg. 1998;85(1):32-6.

12. Tander B, Pektas O, Bulut M. Utility of peritoneal drains in children with uncomplicated perforated appendicitis. Paediatr Surg Intern. 2003;19(17):54850.

13. Pai D, Sharma A, Kanungo R, Jagdish S, Gupta A. A Gupta-Role of drains in perforated duodenal ulcer patients: a prospective controlled study. J Surg. 1999;69(3):210-3.

14. Patil PV, Kamat MM, Hindalekar MM. Spectrum of perforative peritonitis: a prospective study of 150 cases. Bombay Hospital J. 2012;54(1):38-50.

15. Rao M, Samee AA, Khan SM. Hollow viscous perforation: a retrospectum study. Intern J Sci Res. 2015;6(3):3250-4.

16. Archampong EQ. Operative treatment of typhoid perforation at the bowel. Br Med Jr. 1969;3:237.

17. Budhraja SN. Peritonitis- an analysis of 117 cases. Ind Jr Surg. 1973;35:456-64.

18. DeBakey M. Acute perforated gastroduodenal ulceration. Surg. 1940;8;852-84.

19. Oschnner AJ. Sherren Quoted by Dutta S. JIMA;1973:61(5):235.

20. Sinha S, Tiwari C, Sharma RR. HSD primary definitive surgery for duodenal ulcer perforation and haemorrhage. Ind Jr Surg. 1981;44:821-3.

Cite this article as: Garg RK, Gupta R, Kailasia Y, Chhari AK, Jain M, Dubey C. Spectrum of nontraumatic perforation peritonitis: a prospective study of 277 cases with special reference to morbidity and mortality. Int Surg J 2016;3:1223-8. 